\title{
Waste derived glass ceramic composites prepared by low temperature sintering/sinter-crystallisation
}

\section{Ponsot, R. Detsch, A. R. Boccaccini \& E. Bernardo}

To cite this article: I. Ponsot, R. Detsch, A. R. Boccaccini \& E. Bernardo (2015) Waste derived glass ceramic composites prepared by low temperature sintering/sinter-crystallisation, Advances in Applied Ceramics, 114:sup1, S17-S25, DOI: 10.1179/1743676115Y.0000000044

To link to this article: http://dx.doi.org/10.1179/1743676115Y.0000000044

$$
\begin{aligned}
& \text { (c) } 2015 \text { The Author(s). Published by Taylor \& } \\
& \text { Francis. }
\end{aligned}
$$

\section{曲 Published online: 10 Jul 2015.}

Submit your article to this journal $\pi$

ЏII Article views: 273

Q View related articles ¿

View Crossmark data $\asymp$ 


\title{
Waste derived glass ceramic composites prepared by low temperature sintering/ sinter-crystallisation
}

\author{
I. Ponsot ${ }^{1}$, R. Detsch ${ }^{2}$, A. R. Boccaccini ${ }^{2}$ and E. Bernardo*1
}

Glass-ceramics based on iron rich wastes were produced by direct sintering and by following an innovative approach, combining direct sintering and sinter-crystallisation processes. According to the second method, a layered tile was manufactured by single firing at $900^{\circ} \mathrm{C}$ using a selected combination of wastes for both the porous body and the dense coating layer. The coating layer ('glaze') results from the sinter-crystallisation of a waste derived glass mixed with zircon and recycled borosilicate glass. The glaze sealed the porosity of the body and enhanced both mechanical properties and chemical stability. The results show a near to zero water absorption rate, despite a low geometric density $\left(\sim 2 \mathrm{~g} \mathrm{~cm}^{-3}\right)$, accompanied by a Young's modulus of $\sim 40 \mathrm{GPa}$ and a bending strength of $\sim 30 \mathrm{MPa}$. The chemical stability of the glass-ceramics thus developed was assessed by the application of a toxicity control leaching procedure. Furthermore, cell culture tests were carried out to evaluate the potential cytotoxicity of the materials.

Keywords: Glass-ceramics, Metallurgical waste, Viscous flow sintering, Crystallisation, Cytotoxicity

This paper is part of a special issue on glass and ceramic composites for high technology applications (GlaCERCo)

\section{Introduction}

Vitrification technology has proved to be one of the most successful ways to stabilise inorganic wastes, particularly radioactive waste. ${ }^{1}$ As pointed out by Colombo et al., ${ }^{2}$ the stabilisation of non-radioactive wastes is subjected to sustainability constraints: vitrification may be feasible when waste derived glasses can be used as secondary raw materials, i.e. the costs associated with high temperature treatments are compensated by the value of new glass based products, among which glassceramics are undoubtedly the most established. ${ }^{3}$

In most cases, for the production of glass-ceramics, a glass is first shaped (e.g. by rolling of the melt) and then subjected to a secondary ceramisation treatment, aimed at nucleation and growth of crystalline phases. Further treatments on the glass-ceramic products, such as cutting and polishing, can be additionally requested before commercialisation and final use. ${ }^{4}$

Frit derived or 'sinter-crystallised' glass-ceramics have also raised much interest as a low cost alternative to conventional glass-ceramic manufacturing. ${ }^{5}$ Indeed, if waste glasses are poured just after the homogenisation, the (expensive) refining step is no longer required. Crystallisation occurs more rapidly as a result of surface nucleation, in $1 \mathrm{~h}$ or less, at a selected sintering temperature. ${ }^{6}$ When starting from pressed

${ }^{1}$ Dipartimento di Ingegneria Industriale, Università di Padova, via Marzolo 9, 35131 Padova, Italy

${ }^{2}$ Institute of Biomaterials, Department of Materials Science and Engineering, University of Erlangen-Nuremberg, 91058 Erlangen, Germany

*Corresponding author, email enrico.bernardo@unipd.it fine glass powders, cutting and polishing operations are also minimised.

The viscous flow sintering approach can lead to glassceramics, even avoiding the high temperature melting stage $\left(1350-1400^{\circ} \mathrm{C}\right)$. In fact, wastes, combined with significant amounts of recycled glasses, can be subjected to 'direct sintering'. The dissolution of inorganic waste in the liquid phase provided by the recycled glass and the formation of new silicate and alumino-silicate crystals (similar to those produced by devitrification of waste glasses) support the identification of the products as glass-ceramics, although not derived only from a homogeneous parent glass. ${ }^{3}$

Glass-ceramics from direct sintering have one fundamental advantage and one fundamental disadvantage compared to 'classical' glass-ceramics. As well as for the savings in energy required by the overall manufacturing process, the direct sintering is advantageous for reducing the volatilisation of some pollutants (e.g. fluorides); ${ }^{7}$ on the other hand, some pollutants could remain concentrated in some areas of the samples.

This paper describes the obtainment of glass-ceramics from direct sintering of metallurgical slags, mixed with recycled soda-lime glass (SLG). A new strategyrecently proposed ${ }^{8}$ - combining the advantages of direct sintering and of sinter-crystallisation is also exploited. As illustrated by Fig. 1, 'layered glass-ceramics' (LGCs) could be considered as a third option, besides glassceramics from sinter-crystallisation and direct sintering. A single step treatment causes the direct sintering of a base body formed by a glass/waste mixture and the sinter-crystallisation of a frit, obtained from a glass in turn derived from the same starting materials. 


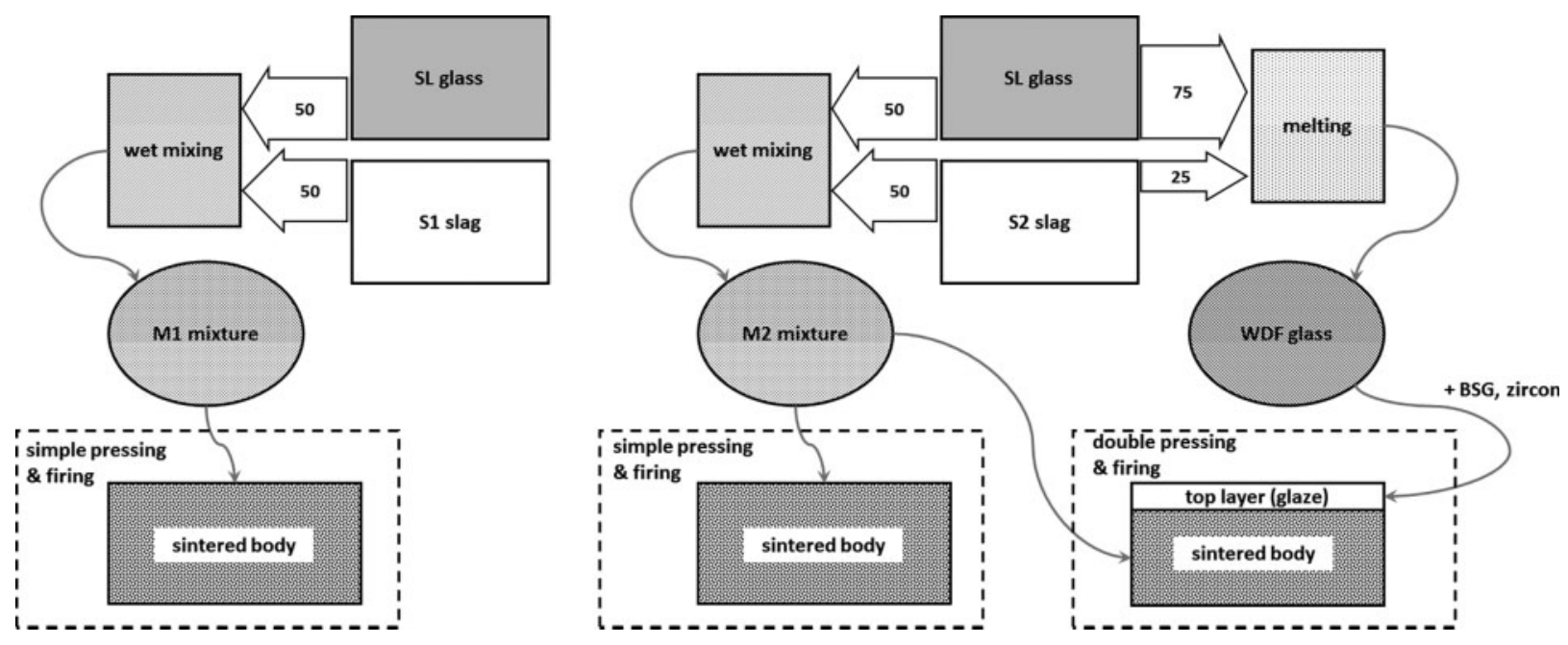

1 Schematic representation of processes adopted for development of glass-ceramics based mainly on metallurgical slags and SLG

The chemical stability needs to be optimised, since the glazed side will be exposed directly to the environment.

Vitrification of waste is reputed to be sustainable, since it is applied only to a limited amount of starting materials; the single firing reduces the costs associated to the deposition of a glaze. In addition, there is a convenient matching of the concept of LGC with the requirements of modern building façades. In fact, there is a growing demand for lightweight tiles, with low water absorption $(<2 \%$, for optimised frost resistance), to be placed vertically, anchored to metal frames, in turn fixed on main building walls. The air gap between the tiles and the wall contributes positively to the thermal insulation (minimising thermal losses, in winter, and minimising overheating, in summer). A solution may come from traditional porcelain stoneware tiles with an engineered porosity, but they are obtained using foaming agents. ${ }^{9}$ Waste derived LGC could be far more convenient than traditional tiles since the porosity of the core, formed by direct sintering, coupled with the strength, low water absorption and possibly pleasant colour of the glaze, could be exploited, thus avoiding the use of valuable natural materials and expensive additives. The direct sinter-crystallisation concept is investigated focusing on suitable combinations of silicate wastes. In addition to characterising the microstructure and mechanical properties of the new glass-ceramics, a study of the possible cytotoxicity of the materials is also presented. The assessment of the in vitro cytocompatibility of waste derived products has the main objective of certifying the safety of these materials for general use.

\section{Experimental}

\section{Sample preparation}

Table 1 reports the chemical compositions of the starting raw materials and the formulations developed from them. 'S1' and 'S2' refer to two types of iron rich slags coming from non-ferrous metallurgy, provided by $\mathrm{KU}$ Leuven (Belgium). As previously reported, ${ }^{10}$ ' $\mathrm{S} 1$ ' is partially crystallised, with fayalite, i.e. Fe(II) silicate $\left(\mathrm{Fe}_{2} \mathrm{SiO}_{4}\right.$ or $\left.2 \mathrm{FeO} . \mathrm{SiO}_{2}\right)$ as the main crystal phase, whereas 'S2' is amorphous. SLG, provided by Sasil SpA (Brusnengo, Italy), corresponds to the fraction of recycled SLG in which the amount of ceramic impurities impedes its extensive reuse in the manufacturing of new glass containers (closed loop recycling). Borosilicate glass (BSG) was also used, which was provided by Nuova OMPI (Piombino Dese, Italy), and derives from discarded pharmaceutical containers. Slags and glasses were first ground separately into fine powders by ball milling and then sieved up to a mean particle size of $90 \mu \mathrm{m}$.

Mixtures of fine powders of SLG and slags, corresponding to the proportions $50 \%$ S1-50\% SLG (M1) and $50 \%$ S2-50\% SLG (M2), were added with water (50\% of the weight of the solid) and homogenised by means of laboratory paddle mixer $(2 \mathrm{~min}$ at $300 \mathrm{rev} \mathrm{min}^{-1}$ ); the resulting pastes were dried in an oven at $80^{\circ} \mathrm{C}$ for $24 \mathrm{~h}$ and then ground again, keeping only granules with a diameter $<150 \mu \mathrm{m}$. Sintering experiments were performed on disc, and tile samples were prepared by pressing dry powders of M1 and M2 mixtures in a cylindrical die (diameter of $20 \mathrm{~mm}$ ) and in a rectangular die (cross-section of $50 \mathrm{~mm} \times 34 \mathrm{~mm}$ ) respectively at a pressure of $40 \mathrm{MPa}$. The samples were further dried at $80^{\circ} \mathrm{C}$ overnight and then fired. The discs were directly heated (direct insertion in furnace running at a selected temperature) at $900-1000^{\circ} \mathrm{C}$ and suddenly extracted after a holding time of $30 \mathrm{~min}$. Tile samples were fired at $900^{\circ} \mathrm{C}$, with a heating rate of $40^{\circ} \mathrm{C} \mathrm{min}-1$; at the end of the holding time (30 min, again), the tiles were rapidly cooled at $\sim 50^{\circ} \mathrm{C} \mathrm{min}^{-1},<600^{\circ} \mathrm{C}$ (with the muffle switched off and muffle door partially open), and then naturally cooled to room temperature (inside the muffle), to minimise thermal shock.

The slag S2 was considered as raw material for a glass frit [waste derived frit (WDF)]. This frit was obtained by melting a second SLG/S2 mixture (75\% SLG-25\% S2) at $1300^{\circ} \mathrm{C}$ for $3 \mathrm{~h}$ and pouring the melt in cold water. The solidified frit fragments were collected, dried at $80^{\circ} \mathrm{C}$, ball milled in an agate jar and finally sieved again up to a maximum dimension of $63 \mu \mathrm{m}$. WDF powders were mixed with other components, such as BSG and zircon mineral [zirconium silicate $\left(\mathrm{ZrSiO}_{4}\right), 0.8 \mu \mathrm{m}$ mean particle size, provided by Industrie Bitossi SpA, Vinci, Italy], in different amounts and pressed into small discs, at $40 \mathrm{MPa}$, later fired at $900^{\circ} \mathrm{C}$.

LGCs were obtained by double pressing in a $50 \mathrm{~mm} \times 34 \mathrm{~mm}$ rectangular die. A base layer of M2 
Table 1 Chemical compositions and formulations of starting wastes, recycled glasses and waste derived glass-ceramics

\begin{tabular}{|c|c|c|c|c|c|c|c|}
\hline Component & S1 & $\mathrm{S} 2$ & SLG & BSG & Mixture 1 (M1) & Mixture 2 (M2) & WDF \\
\hline \multicolumn{8}{|l|}{ Oxides (wt-\%) } \\
\hline $\mathrm{SiO}_{2}$ & 29 & 24 & 71.6 & 72 & 50.5 & 47.8 & 59.7 \\
\hline $\mathrm{FeO}$ & 52 & 32 & & & 26 & 16 & 8 \\
\hline $\mathrm{Al}_{2} \mathrm{O}_{3}$ & 4 & 6 & 1.0 & 7 & 2.5 & $<1$ & 2.2 \\
\hline $\mathrm{Na}_{2} \mathrm{O}$ & $<1$ & $<1$ & 13.5 & 6 & 7 & 7 & 3.7 \\
\hline $\mathrm{K}_{2} \mathrm{O}$ & $<1$ & $<1$ & 0.4 & 2 & $<1$ & $<1$ & $<1$ \\
\hline $\mathrm{MgO}$ & 1 & 1 & 3.9 & & 2.5 & 2.5 & 3.1 \\
\hline $\mathrm{CaO}$ & 2 & 21 & 9.0 & 1 & 5.5 & 15 & 12 \\
\hline $\mathrm{ZnO}$ & 7 & 7 & & & 3.5 & 3.5 & 1.7 \\
\hline $\mathrm{B}_{2} \mathrm{O}_{3}$ & $<1$ & $<1$ & & 12 & $<1$ & $<1$ & \\
\hline \multicolumn{8}{|c|}{ Formulations (wt-\% balances) } \\
\hline M1 & 50 & & 50 & & & & \\
\hline M2 & & 50 & 50 & & & & \\
\hline WDF & & 25 & 75 & & & & \\
\hline Glaze for LGC* & & & & 15 & & & 40 \\
\hline
\end{tabular}

* Remaining $45 \%$ represented by zircon $\left(\mathrm{ZrSiO}_{4}\right)$ mineral.

mixture was first subjected to light pressing (10 MPa) and subsequently coated with WDF/glass/zircon powders (a weight proportion WDF-BSG-Zircon of 40-1545 was the optimum one) in an amount corresponding to a surface density of $0.080 \mathrm{~g} \mathrm{~cm}^{-2}$. The coating was performed by leaving the pressed powders inside the die, removing only the plunger; the WDF powders were manually passed through a sieve positioned over the open die. After repositioning the plunger, the interpenetration between the WDF/glass/zircon powders and the substrate was achieved by secondary pressing at $40 \mathrm{MPa}$. LGCs were subjected to the same thermal treatment applied to M1 and M2.

\section{Characterisation}

WDF, in form of both coarse and fine powder (particles sizes $>1 \mathrm{~mm}$ and $<63 \mu \mathrm{m}$ respectively), was subjected to differential thermal analysis (DTA) (DSC 404, Netzsch Gerätebau GmbH, Selb, Germany, 25-1200 ${ }^{\circ}$,

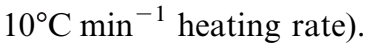

X-ray diffraction analyses (Bruker D8 Advance, Karlsruhe, Germany) were performed on powdered samples, employing $\mathrm{Cu} K_{\alpha}$ radiation $(0.15418 \mathrm{~nm})$, in the interval $2 \theta=10-60^{\circ}$. Phase identification was achieved by means of the Match! program package (Crystal Impact GbR, Bonn, Germany), supported by data from PDF-2 database (ICDD-International Centre for Diffraction Data, Newtown Square, PA).

Immersion in boiling water was used for the evaluation of the water absorption, according to the current norm (ISO 10545-3). The apparent density of the sintered materials was estimated by means of Archimedes' principle.

The elastic modulus was measured by non-destructive resonance frequency testing (GrindoSonic Mk5, Leuven, Belgium). The bending strength was measured on small beams of $\sim 35 \mathrm{~mm} \times 4 \mathrm{~mm} \times 4 \mathrm{~mm}$, cut from bigger samples. All beams were carefully polished to a $5 \mu \mathrm{m}$ finish and chamfered at the edges, using diamond tools. Four point bending tests ( $24 \mathrm{~mm}$ outer span, $8 \mathrm{~mm}$ inner span) were performed using an Instron 1121 UTS (Instron, Danvers, MA), with a crosshead speed of $1 \mathrm{~mm} \mathrm{~min}^{-1}$; each data point represents the average of at least 10 individual tests. The layered samples were tested by positioning the frit derived layer on the tensile side. The morphological features of sintered samples were characterised by scanning electron microscopy (SEM-ESEM Quanta 200, FEI Company, Eindhoven, The Netherlands).

The release of heavy metals was evaluated by application of a toxicity control leaching procedure (TCLP) prepared according to European Standard for waste toxicity evaluation (EN 12457-2). Fragments from bending strength tests were placed in an extraction solution consisting of distilled water, with a $\mathrm{pH}$ value of $\sim 7$, for a liquid/solid ratio of 20 , and softly stirred at $25^{\circ} \mathrm{C}$ for $24 \mathrm{~h}$. The resulting solutions were filtered through a $0.6 \mu \mathrm{m}$ filter and analysed using inductively coupled plasma (ICP; SPECTRO Analytical nstruments GmbH, Kleve, Germany).

Selected samples were subjected to cytotoxicity tests. These tests were applied on small discs (1 mm thickness, $13 \mathrm{~mm}$ diameter) prepared as above, but used after gradual polishing, up to a $350 \mathrm{~nm}$ finish, by means of diamond tools. Cytotoxicity tests were performed according to a 'direct' method. ${ }^{10}$ A suspension of mouse embryonic fibroblast cells was cultured for $24 \mathrm{~h}$ in a Dulbecco's modified Eagle medium containing 10\% foetal bovine serum and $1 \%$ penicillin-streptomycin, at $37^{\circ} \mathrm{C}$, in a humidified atmosphere incubator (air, with $5 \% \mathrm{CO}_{2}$ ). In the direct method, cells were seeded on the samples (selected sintered glass-ceramics and SLG, used as a reference) for a $24 \mathrm{~h}$ incubation time. For cell viability measurements, water soluble tetrasodium assay (WST1) (Sigma-Aldrich, Germany) was used as recommended by the manufacturer. Qualitative evaluation was performed using a fluorescence microscope ZEISS Scope A1, with digital camera AxioCam Icc $1 \mathrm{~S} /$ N 28591065, HXP120C Kübler fluorescence light source, BF, light blue (Dapi fluorescence markers) and green (calcein markers), and images were analysed using Software ZEN (blue edition) (Carl Zeiss MicroImaging $\mathrm{GmbH})$.

\section{Results and discussion}

The preliminary firing treatments, on small disc samples, were aimed at evidencing the impact of temperature on density and water absorption, critical to applications in the building industry. ${ }^{9}$ From Fig. 2, it can be seen that the two slags, mixed with SLG, led to samples with quite particular density and water absorption trends. 


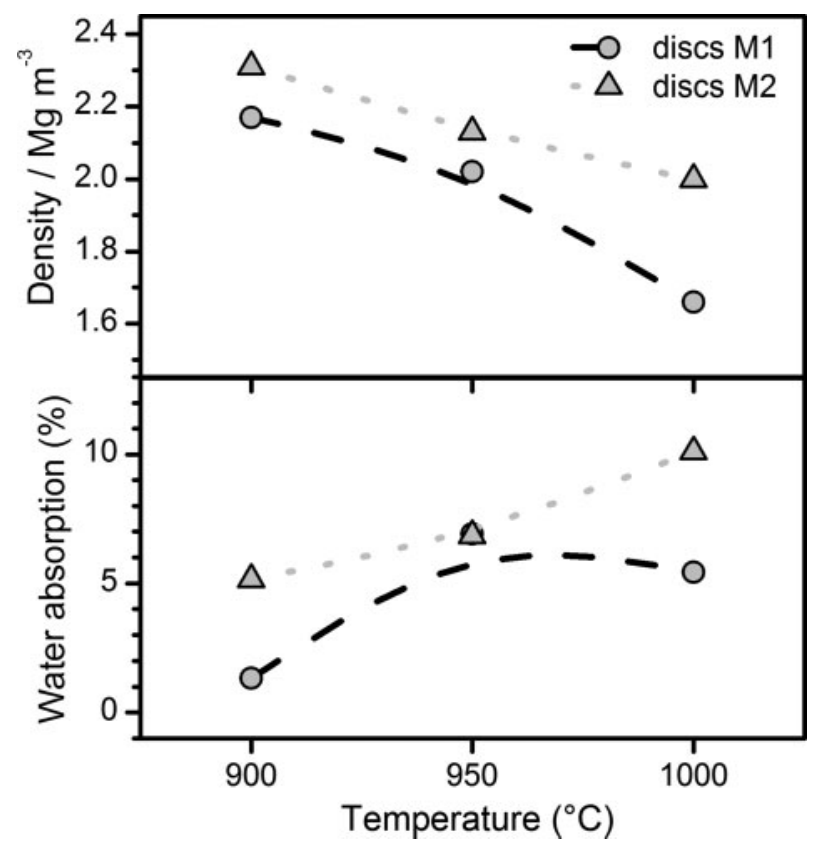

2 Density and water absorption of samples from direct sintering (preliminary firing tests)

Increasing the temperature of sintering from 900 to $1000^{\circ} \mathrm{C}$, the density almost linearly decreased, in parallel with a visibly growing porosity. S1 was confirmed to lead to lighter bodies, with the density curve corresponding to M1 mixtures always lower than those of M2 mixtures; the water absorption, on the contrary, was minimised for M1 samples.

The formation of pores is attributed to oxygen release (abundant in S1 and S2 slags). It may be observed from Table 1 that iron is in the $\mathrm{Fe}^{2+}(\mathrm{FeO})$ state in the starting slags; for $\mathrm{S} 1$, in particular, this is consistent with the presence of fayalite $\left(\mathrm{Fe}_{2} \mathrm{SiO}_{4}\right.$, $\left.\mathrm{PDF} \# 09-0484\right)$, as shown in Fig. 3. However, a first oxidation by direct slag/air interaction (e.g. 'oxygenolysis' of $\mathrm{Fe}_{2} \mathrm{SiO}_{4}$, yielding $\mathrm{SiO}_{2}$ and $\mathrm{Fe}_{2} \mathrm{O}_{3}$ or $\left.\mathrm{Fe}_{3} \mathrm{O}_{4}\right)^{10}$ could be followed by reduction, as a consequence of slag/glass interactions (the glass chemistry affects the stability of the iron oxides: this has been recently observed with SLG/basalt mixtures, leading to highly porous glass-ceramics). ${ }^{11}$

The diffraction patterns of M1 and M2 fired samples, in Fig. 3, may be seen as a confirmation of the oxidation/reduction sequence. In fact, both magnetite $\left(\mathrm{Fe}_{3} \mathrm{O}_{4}, \mathrm{PDF} \# 86-\right.$ 1356) and hematite $\left(\mathrm{Fe}_{2} \mathrm{O}_{3}, \mathrm{PDF} \# 72-0469\right)$ appear in samples fired at $900^{\circ} \mathrm{C}$, for both formulations. For $\mathrm{M} 1$, cristobalite (crystalline $\mathrm{SiO}_{2}, \mathrm{PDF} \# 82-0512$ ) is also evident, as a result of fayalite decomposition. The magnetite peaks (see, in particular, the strongest line at $2 \theta \approx 35^{\circ}$ ), for $\mathrm{M} 1$, become stronger with increasing firing temperature, whereas those of hematite (strongest line at $2 \theta \approx 33^{\circ}$ ) become weaker, consistently with a reduction reaction, providing oxygen release $\left(6 \mathrm{Fe}_{2} \mathrm{O}_{3} \rightarrow 4 \mathrm{Fe}_{3} \mathrm{O}_{4}+\mathrm{O}_{2}\right)$.

The glass/slag interactions are further testified by newly formed silicates, relatively rich in silica (limited in both S1 and S2, abundant in SLG). For both formulations, the presence of pyroxene is confirmed, corresponding to the general formula $\mathrm{CaMg}_{x} \mathrm{Fe}_{1(x} \mathrm{Si}_{2} \mathrm{O}_{6}$ (the position and the intensity of peaks are well matched by $\mathrm{CaMg}_{0.34} \mathrm{Fe}_{0.66} \mathrm{Si}_{2} \mathrm{O}_{6}, \mathrm{PDF} \# 87-0701$, and $\mathrm{CaMg}_{0.52-}$ $\left.\mathrm{Fe}_{0.48} \mathrm{Si}_{2} \mathrm{O}_{6}, \mathrm{PDF} \# 87-0701\right)$. The chemistry of this phase is probably even more complicated, since it can incorporate additional ions, e.g. $\mathrm{Zn}^{2+}$ as well as $\mathrm{Al}^{3+}$ (from slags). ${ }^{12}$ Finally, samples from S2 slag, richer in $\mathrm{CaO}$, feature wollastonite $\left(\mathrm{CaSiO}_{3}, \mathrm{PDF} \# 84-0655\right)$.

The formation of wollastonite could be seen as a reasonable cause for the observed enhanced water absorption for M2 samples. The viscous flow sintering of the glass phase could fill the external porosity (the sample M1 fired at $900^{\circ} \mathrm{C}$, as an example, exhibited a water absorption of only $\approx 1 \%$ ); however, the presence of rigid inclusions could delay the glass flow, ${ }^{13}$ especially in the case of inclusions represented by highly elongated crystals, like those usually associated with silicates. ${ }^{14}$

As shown by Fig. $4 a$, tiles from mixtures M1 and M2, fired at $900^{\circ} \mathrm{C}$, were quite different. M1, presenting a black colour, became smooth and particularly brilliant, after polishing (up to $5 \mu \mathrm{m}$ ), in good analogy with porcelain stoneware and natural stones. On the contrary, M2, featuring a red colour, remained quite opaque. The difference is evident also in the high magnification details, in Fig. $4 b$ and $c$; the M1 sample exhibited isolated pores, whereas the M2 sample presented widespread porosity, determining the observed opacity by substantial scattering of reflected light and the smoothness of the glazed surface after polishing.

The water absorption for tile samples, as reported in Table 2, is in good agreement with that of disc samples, despite the difference in heating and cooling (the conditions applied to tile samples were conceived to minimise thermal gradients, in bigger samples, upon heating, and thermal shock, upon cooling). Thus, M1 samples obtained from direct sintering exhibit potential as lightweight tiles, even in the absence of a glaze; the complex of properties (density slightly higher than $2 \mathrm{~g} \mathrm{~cm}^{-3}$, low water absorption, bending strength $>30 \mathrm{MPa}$ ) compares favourably with that of porous lightweight porcelain. ${ }^{9} \mathrm{M} 2$ samples, on the contrary, cannot be accepted due to the excessive water absorption.

Following the scheme of Fig. 1, the deposition of a glaze was considered as a possible improvement of M2 samples. This glaze derived from the same starting raw materials (SLG and S2 slag) than M2 samples, but with a different balance. In fact, the mixing of $75 \mathrm{wt}-\%$ SLG with $25 \% \mathrm{~S} 2$, instead of $50 \%$ SLG and $50 \% \mathrm{~S} 2$, could lead to a glass frit (WDF) with enhanced silica content, promoting the chemical stability.

WDF was found to be sensitive to surface nucleation. As shown in Fig. 5, fine glass powders (with large specific surface) exhibited a significant crystallisation exothermic peak at $\sim 900^{\circ} \mathrm{C}$; on the contrary, coarse fragments (with limited specific surface) did not present any significant exothermic peak. Interestingly, WDF is also a suitable candidate for sinter-crystallisation, i.e. crystallisation with concurrent crystallisation; in fact, dense glass-ceramics can be obtained by sintering at the crystallisation temperature (temperature of the exothermic peak, $T_{\mathrm{C}}$ ) if this temperature far exceeds the dilatometric softening temperature, recognised as the minimum temperature for extensive viscous flow. ${ }^{14}$ In the present case, the dilatometric softening temperature was not determined, but there is a particularly wide gap (nearly $300^{\circ} \mathrm{C}$ ) between the transition temperature $\left(T_{\mathrm{G}}\right)$ and $T_{\mathrm{C}}$; considering that the dilatometric softening occurs only slightly above $T_{\mathrm{G}}$, WDF had effectively develop a dense glass-ceramic layer after sintering at $900^{\circ} \mathrm{C}^{6}$ 

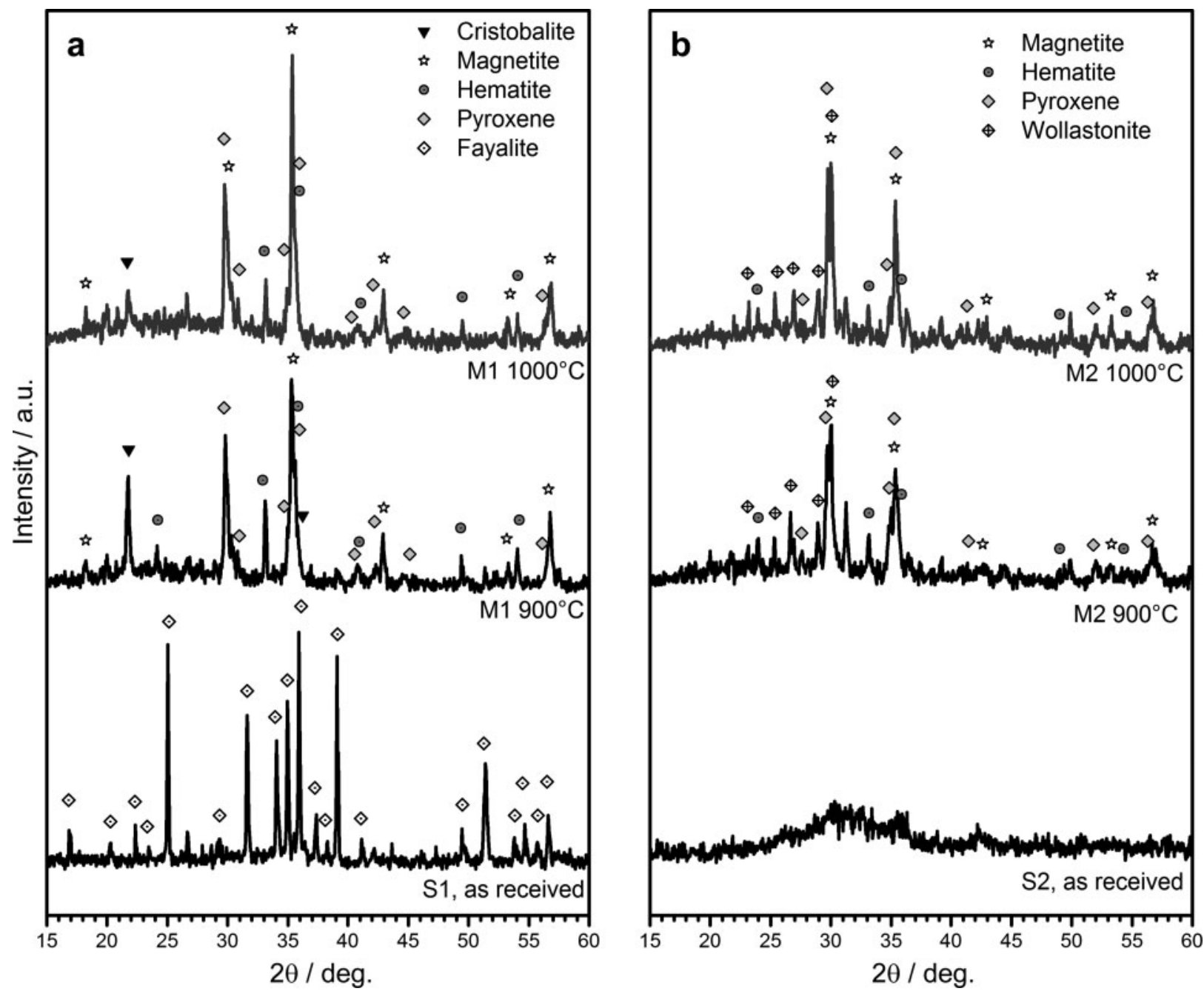

3 X-ray diffraction patterns of selected samples from direct sintering (preliminary firing tests)
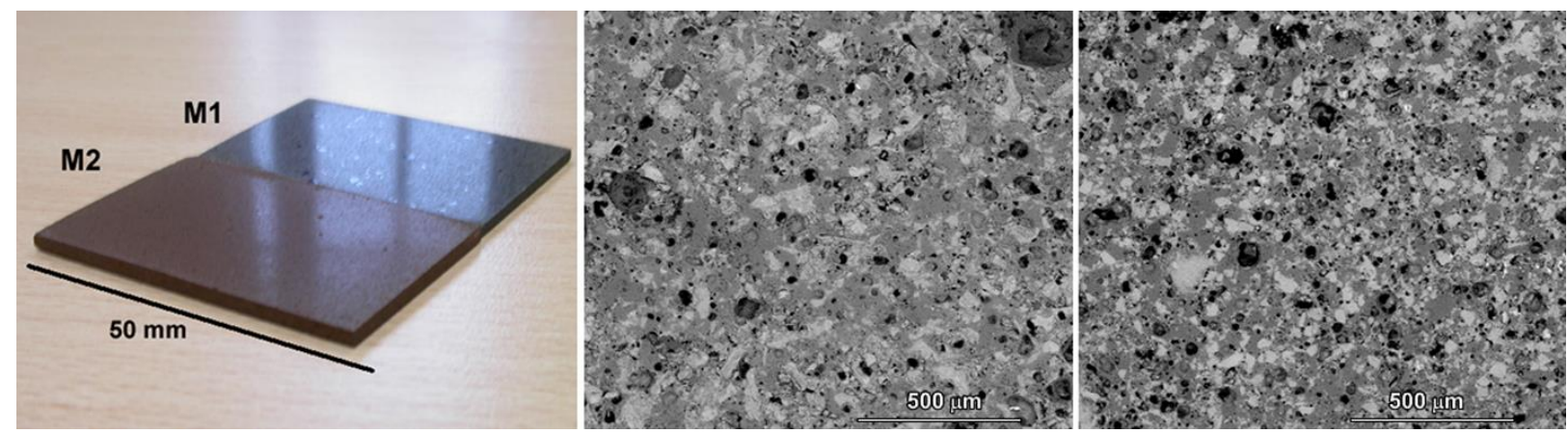

$4 a$ aesthetic appearance of tiles samples from M1 and M2 mixtures; $b$ microstructural detail of sample M1; $c$ microstructural detail of sample M2

The colour and the shrinkage of these samples remain as open issues concerning the application of WDF as a glaze for M2 bodies. In fact, pure WDF discs exhibited a quite unpleasant yellow-brown colour and far higher shrinkage $(\sim 26 \%)$ than M2 samples $(6.2 \%)$, after firing at $900^{\circ} \mathrm{C}$; such mismatch could cause the development of cracks between the substrate and the glaze in LGCs. This effect was corrected by considering WDF mixed with zircon and BSG powders. Zircon (well known white pigment) improved the aesthetic appearance, leading to samples with a much lighter colouration, but also, its addition limited the densification. The shrinkage of the sample containing $45 \%$ zircon fell dramatically, at $\sim 1 \%$, while the water absorption was $>7 \%$. The addition of BSG enhanced the viscous flow sintering, being not subjected to crystallisation. Figure $6 a$ shows that the progressive replacement of WDF with BSG, starting from a sample with WDF and zircon in the 55/45 weight proportion, effectively led to samples with moderate shrinkage and low water absorption. For the WDF/ BSG/zircon proportion of $40 / 15 / 45$, the shrinkage matched that of the M2 sample, whereas the water absorption reached $2 \%$, which is the above mentioned threshold limit for optimum frost resistance. 
Table 2 Physical and mechanical properties of waste derived glass-ceramics

\begin{tabular}{lllll}
\hline Sample & Density/Mg m & Water absorption/\% & Elastic modulus/GPa & Bending strength/MPa \\
\hline M1 & $2.12 \pm 0.03$ & 0.6 & $44.3 \pm 4.1$ & $35.9 \pm 9.0$ \\
M2 & $2.08 \pm 0.04$ & 5.8 & $37.9 \pm 2.4$ & $27.6 \pm 2.7$ \\
LGC (M2 core) & $2.16 \pm 0.05$ & 1.7 & $42.3 \pm 6.5$ & $31.4 \pm 4.7$ \\
\hline
\end{tabular}

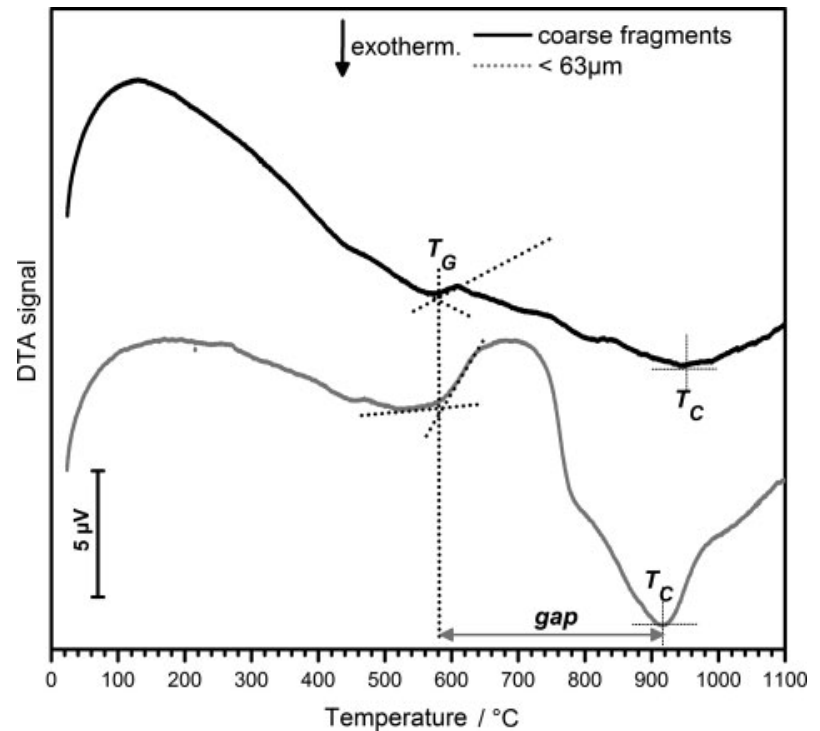

5 DTA analysis of fine and bulk powders of WDF

The glaze can still be considered as the sinter-crystallisation of WDF. In fact, from Fig. $6 b$, it can be noted that the strongest diffraction peaks correspond to zircon ( $\left.\mathrm{ZrSiO}_{4}, \mathrm{PDF} \# 71-0991\right)$; however, peaks attributable to both wollastonite and pyroxene (see the matching of positions with the pattern for M2) are still visible.

The LGC sample from direct sintering of M2 mixture accompanied by sinter-crystallisation of WDF/BSG/ zircon mixture is shown in Fig. 7a. The figure evidences the light colour and the smoothness of the glazed surface after polishing. The coating is uniform and evidently crack free; this is further confirmed by the SEM image in Fig. $7 b$, clearly showing the good interpenetration of the glaze (the high atomic weight of $\mathrm{Zr}$ makes the zircon containing glaze lighter, in backscattered electron images), still featuring some residual porosity, with the more porous body from the M2 mixture. 'Islands' corresponding to BSG and WDF are evidenced in Fig. $7 c$ (in particular, due to the low atomic weight of $\mathrm{B}, \mathrm{BSG}$ rich zone appears darker). Finally, the previously discussed silicate crystals (wollastonite and pyroxene) are visible in the WDF rich areas, in the high magnification detail of Fig. $7 d$, while iron oxides are not visible as separate particles. Interestingly, fibrous silicate crystals appear concentrated at the interface with zircon particles, as a further proof of surface nucleation.

As reported in Table 2, the introduction of a glaze, in the LGC sample, did not particularly enhance the density, compared to M2; on the contrary, the water absorption (measured on a dense disc with the composition of the glaze) was much lower than that of M2. Elastic modulus and bending strength improved and were quite close to those of M1 sample. LGC could be actually considered a good candidate for the manufacturing of ventilated façades, like M1, but with the additional advantage of a much lighter colour.
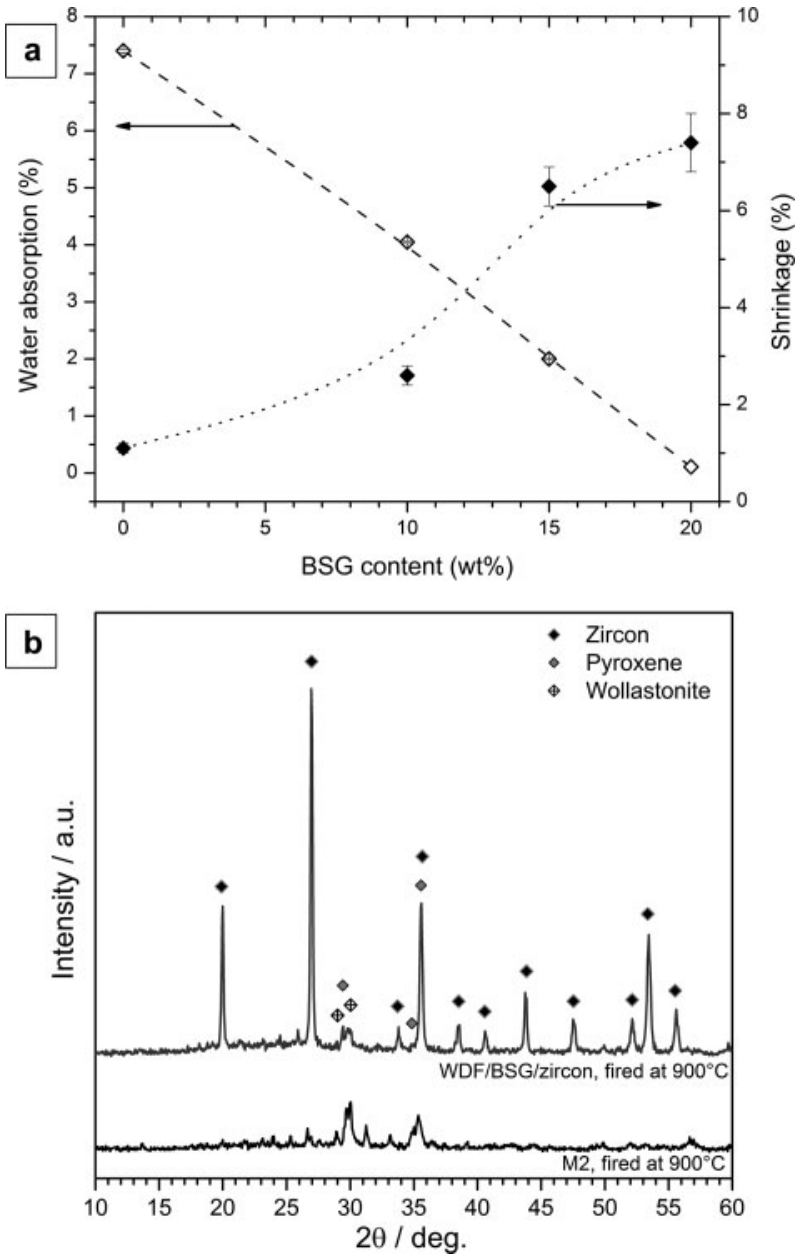

6 a water absorption/shrinkage evolution with increasing amount of BSG glass in frit derived glass-ceramics fired at $900^{\circ} \mathrm{C}$, for $30 \mathrm{~min} ; b$ X-ray diffraction pattern of optimised glaze $(W D F / B S G / z i r c o n=40 / 15 / 45)$

The glass-ceramics produced were also evaluated in terms of stabilisation of pollutants, by application of TCLP. The tile sample from M1 mixture, according to the leaching data reported in Table 3 , is chemically stable, with all metal ions well below the thresholds for inert materials, according to European Norm EN 12457. The tile from M2 had some ions above the thresholds (in particular $\mathrm{Sb}$ ); the enhanced specific surface, due to open porosity (in turn associated with the observed high water absorption), maximised the interaction between material and solution, favouring the leaching. In analogy with water absorption, the leaching was also improved by application of a glaze, with all metal ions well below the threshold for inert materials for a test applied on WDF/BSG/zircon glass-ceramic.

In addition to TCLP, research on waste derived materials must also characterise the potential cytotoxicity of products derived from industrial residues ${ }^{15}$. Such assays can be carried out by standard cell 


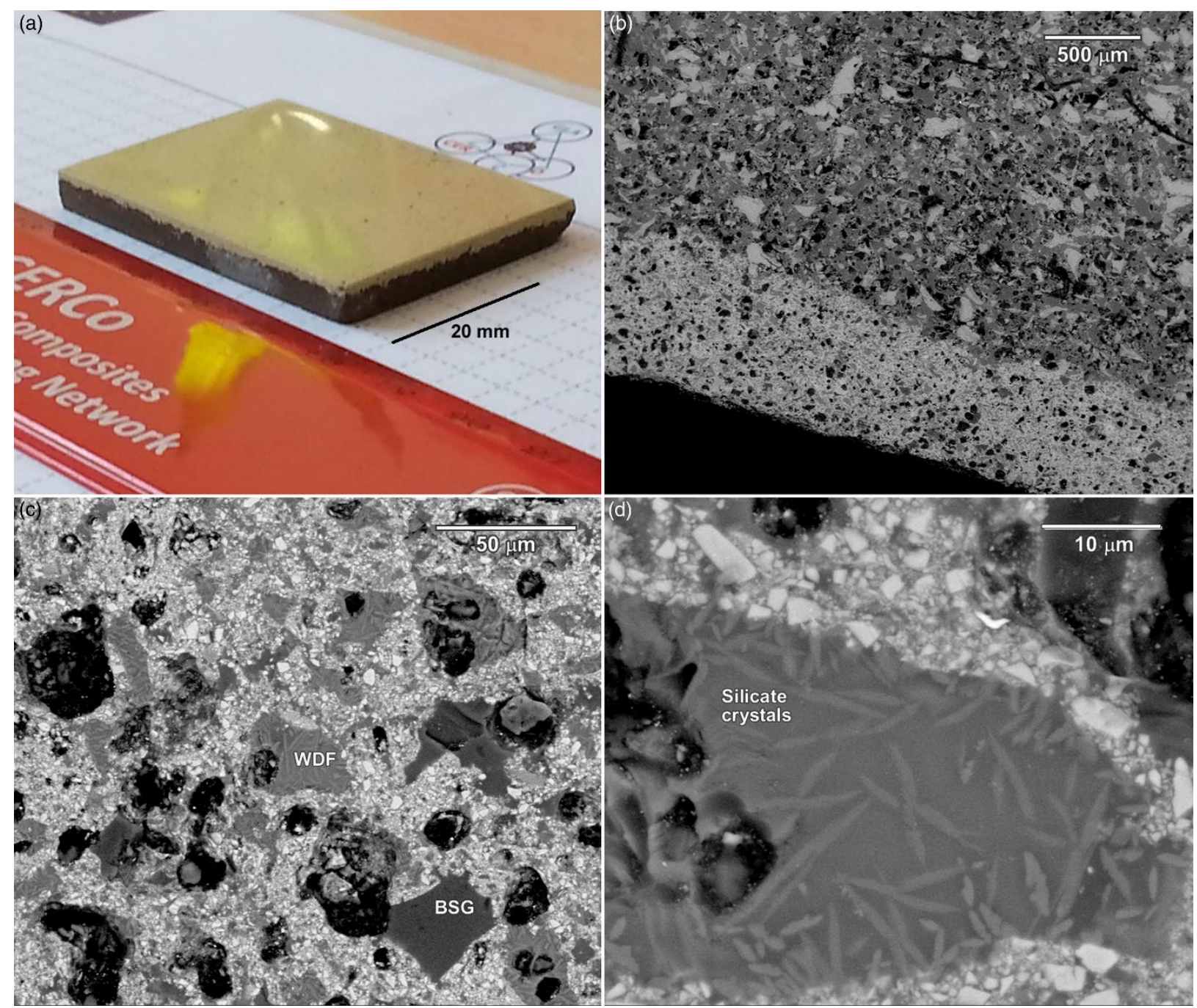

7 Aesthetic appearance and microstructural details of LGC sample, derived from S2 slag: a photographic view; $b$ interface (SEM image); $c, d$ high magnification details of the glaze (SEM images)

Table 3 Leaching results of samples heated at $900^{\circ} \mathrm{C}$ for $30 \mathrm{~min}$ with $40^{\circ} \mathrm{C} \mathrm{min}^{-1}$ rate

\begin{tabular}{|c|c|c|c|c|c|}
\hline \multirow[b]{2}{*}{ Element } & \multicolumn{3}{|c|}{ Leachate/ppm } & \multicolumn{2}{|c|}{ Limits [UE]/ppm } \\
\hline & M1 & M2 & LGC (glaze) & Inert material & Non-hazardous material \\
\hline As & 0.0241 & 0.3284 & 0.0309 & 0.05 & 0.2 \\
\hline $\mathrm{Ba}$ & 0.0514 & $>0.7382$ & 0.0157 & 2 & 10 \\
\hline $\mathrm{Cd}$ & $<0.0002$ & $<0.0002$ & $<0.0002$ & 0.004 & 0.1 \\
\hline $\mathrm{Cr}$ & 0.0046 & 0.0226 & 0.1152 & 0.05 & 1 \\
\hline $\mathrm{Cu}$ & 0.0239 & 0.0602 & 0.0090 & 0.2 & 5 \\
\hline Mo & 0.0148 & 0.1684 & 0.0760 & 0.05 & 1 \\
\hline $\mathrm{Ni}$ & 0.0059 & 0.0045 & 0.0024 & 0.04 & 1 \\
\hline $\mathrm{Pb}$ & $<0.0047$ & $<0.0047$ & $<0.0047$ & 0.05 & 1 \\
\hline $\mathrm{Sb}$ & $<0.0099$ & 0.2498 & $<0.0099$ & 0.006 & 0.07 \\
\hline $\mathrm{Se}$ & $<0.0122$ & 0.0697 & $<0.0122$ & 0.01 & 0.05 \\
\hline $\mathrm{Zn}$ & 0.0281 & $<0.0203$ & $<0.0203$ & 0.4 & 5 \\
\hline
\end{tabular}

culture methods. ${ }^{16}$ Even if such cell culture methods were first reported for glass-ceramics produced from waste more than 15 years ago, ${ }^{15}$ they have not been widely applied in most subsequent studies, a situation that current research is tackling ${ }^{10,17}$ aiming at enhancing the social acceptance and industrial attractiveness of waste derived materials.

Figure 8 reports the cell viabilities (left), after a $24 \mathrm{~h}$ exposition of the materials in a culture of mouse embryonic fibroblasts, and the morphology and spreading of cells on sample surfaces (right), with blue and green evidencing the nuclei (Dapi markers) and the cytoplasms (calcein markers) respectively.

The results show that SLG is the most viable sample in terms of cellular activity. Indeed, its composition is similar to that of simple biocompatible glasses, as $\mathrm{Si}, \mathrm{O}$, $\mathrm{Na}$ and $\mathrm{Ca}$, present in high majority, are elements of relevance for cellular growth. ${ }^{10,18}$ The cell viability decreased in M1 and in the glaze for LGC, in agreement with the lower percentages of the previously mentioned 

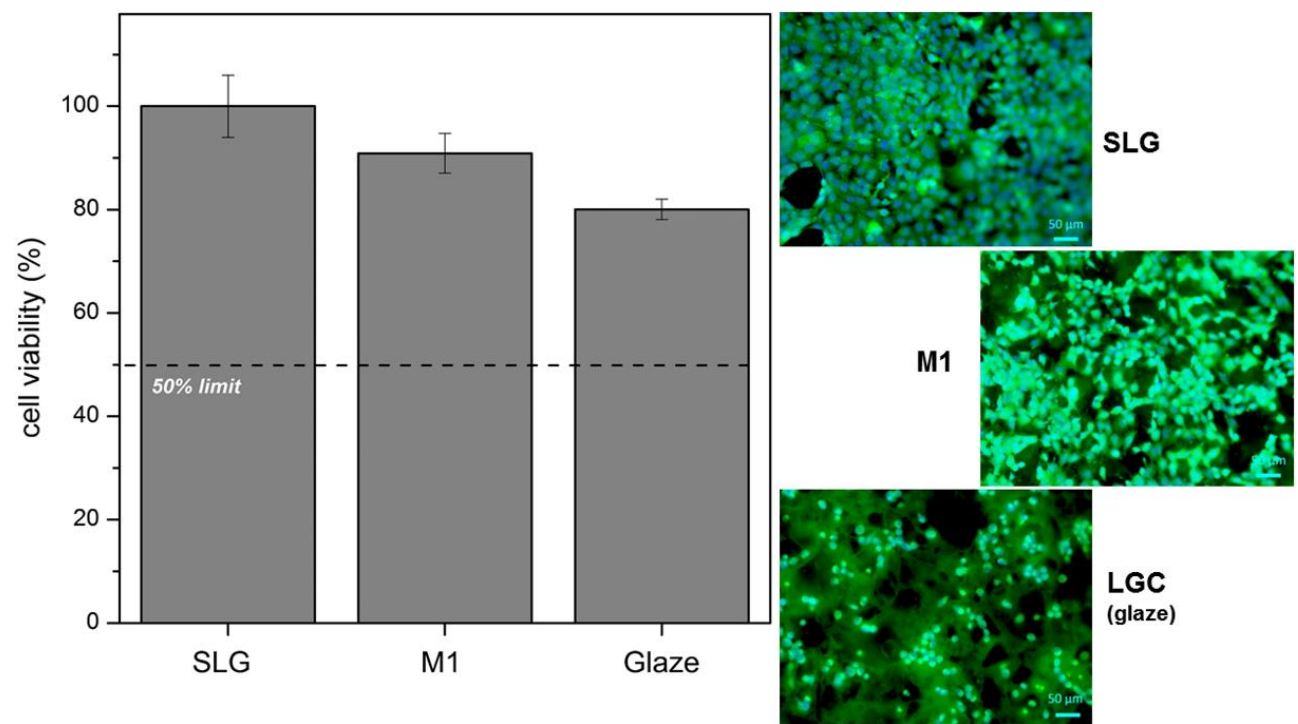

8 Cell viability (in \%) referred to commercial SLG (left); fluorescent microscope images of samples from direct cytotoxicity test (right)

elements, but remained substantial (well above 50\%, considered as a threshold for toxicity). As previously found with samples from $\mathrm{S} 1$ and $\mathrm{S} 2$ residues combined with $\mathrm{BSG},{ }^{10}$ the cells exhibited spreading and mutual interconnections, with an elongated morphology, which are well recognised features to indicate biocompatibility. ${ }^{16,18}$ The results are undoubtedly preliminary (as an example, 'indirect' tests, in which samples were placed in a separate cell culture medium under standard conditions, are still in progress); however, the observed cytocompatibility is in broad agreement with the chemical stability results assessed by TCLP leaching test.

\section{Conclusions}

The results of this investigation lead to the following conclusions.

(i) Direct sintering of metallurgical slag (S1) and SLG results in lightweight glass-ceramics, with limited water absorption, mechanical properties comparable to those of lightweight porcelain tiles and chemical stability.

(ii) The excessive water absorption and the poor chemical stability of glass-ceramics from the mixing of SLG with another metallurgical slag (S2) can be improved by application of a glaze.

(iii) A single step thermal treatment can determine both direct sintering of a waste derived base body and sinter-crystallisation of the glaze.

(iv) A waste derived glaze can be adjusted, in terms of colour, shrinkage and viscous flow, by addition of zircon and recycled BSG.

(v) LGCs, comprising a waste derived core and a waste derived glaze, could find applications in the building industry as lightweight tiles, e.g. in ventilated façades.

(vi) The silicate compositions investigated were chemically stable and cytocompatible under the cell culture conditions considered.

\section{Acknowledgements}

The authors thank Dr C. Furlan and Dr G. Zanmarchi (University of Padova) for the SEM and the ICP analysis respectively. The authors gratefully acknowledge also Dr. Y. Pontikes (Department of Metallurgy and Materials Engineering, Katholieke Universiteit Leuven, Belgium) for supplying S1 and S2 slags, and the support of the European Community's Seventh Framework Programme through a Marie-Curie Research Training Network ('GlaCERCo-ITN', g.a. no. 264526).

\section{References}

1. U.S. Environmental Protection Agency: 'Handbook on vitrification technologies for treatment of hazardous and radioactive waste, Report EPA/625/R-92/002', 1992, Washington, DC, Office of Research and Development, U.S. Environmental Protection Agency.

2. P. Colombo, G. Brusatin, E. Bernardo and G. Scarinci: 'Inertization and reuse of waste materials by vitrification and fabrication of glass-based products', Curr. Opin. Solid State Mater. Sci., 2003, 7, 225-239.

3. R. D. Rawlings, J. P. Wu and A. R. Boccaccini: 'Glass-ceramics: their production from wastes-a review', J. Mater. Sci., 2006, 41, 733-761.

4. W. Höland and G. Beall: 'Glass-ceramic technology', 1st edn; 2002, Westerville, $\mathrm{OH}$, The American Ceramic Society.

5. L. M. Schabbach, F. Andreola, E. Karamanova, I. Lancellotti, A. Karamanov and L. Barbieri: 'Integrated approach to establish the sinter-crystallization ability of glasses from secondary raw material', J. Non-Cryst. Solids, 2011, 357, 10-17.

6. M. Marangoni, I. Ponsot, R. Kuusik and E. Bernardo: 'Strong and chemically inert sinter crystallised glass ceramics based on Estonian oil shale ash', Adv. Appl. Ceram., 2014, 113, 120-128.

7. I. Ponsot, R. Falcone and E. Bernardo: 'Stabilization of fluorinecontaining industrial waste by production of sintered glassceramics', Ceram. Int., 2013, 39, 6907-6915.

8. M. A. Binhussain, M. Marangoni, E. Bernardo and P. Colombo: 'Sintered and glazed glass-ceramics from natural and waste raw materials', Ceram. Int., 2014, 40, 3543-3551.

9. E. Bernardo, M. De Lazzari, P. Colombo, A. Saburit Llaudis and F. J. Garcì-Ten: 'Lightweight porcelain stoneware by engineered $\mathrm{CeO}_{2}$ addition', Adv. Eng. Mater., 2010, 12, 65-70.

10. I. Ponsot, Y. Pontikes, G. Baldi, R. K. Chinnam, R. Detsch, A. R. Boccaccini and E. Bernardo: 'Magnetic glass ceramics by sintering of borosilicate glass and inorganic waste', Materials, 2014, 7, 5565-5580.

11. M. Marangoni, M. Secco, M. Parisatto, G. Artioli, E. Bernardo, P. Colombo, H. Altlasi, M. Binmajed and M. Binhussain: 'Cellular glass-ceramics from a self foaming mixture of glass and basalt scoria', J. Non-Cryst. Solids, 2014, 403, 38-46.

12. J. Ma. Rincón, M. Romero and A. R. Boccaccini: 'Microstructural characterisation of a glass and a glass-ceramic obtained from municipal incinerator fly ash', J. Mater. Sci., 1999, 34, 4413-4423. 
13. M. J. Pascual, A. Durán, M. O. Prado and E. D. Zanotto: 'Model for sintering devitrifying glass particles with embedded rigid fibers', J. Am. Ceram. Soc., 2005, 88, 1427-1434.

14. A. Ray and A. N. Tiwari: 'Compaction and sintering behaviour of glass-alumina composites', Mater. Chem. Phys., 2001, 67, 220-225.

15. A. R. Boccaccini, M. Petitmermet and E. Wintermantel: 'Glassceramics from municipal incinerator fly ash', Ceram. Bull., 1997, 76, (11), 75-78.
16. T. D. Pollard, W. C. Earnshaw and J. Lippincott-Schwartz: 'Cell biology', 2nd edn; 2008, Philadelphia, PA, Elsevier Inc.

17. I. Ponsot, E. Bernardo, E. Bontempi, L. Depero, R. Detsch, R. K. Chinnam and A. R. Boccaccini: 'Recycling of pre-stabilized municipal waste incinerator fly ash and soda-lime glass into sintered glass-ceramics', J. Cleaner Prod., 2015, 89, 224-230.

18. A. Hoppe, N. S. Güldal and A. R. Boccaccini: 'A review of the biological response to ionic dissolution products from bioactive glasses and glass ceramics', Biomaterials, 2011, 32, 2757-2774. 